\title{
Is asthma treatment affordable in developing countries?
}

\author{
John P Watson, Richard A Lewis
}

\begin{abstract}
Background - A study was undertaken to assess whether the therapeutic aspects of published international asthma management guidelines are practically applicable in developing countries.

Methods - Questionnaires were sent to expatriate doctors working in developing countries.

Results- Forty one replies were received from 24 countries in Africa and Asia. Oral salbutamol was prescribed "usually" or "often" by 35 of the 41 respondents, theophyllines by 30, inhaled bronchodilators by 12 , inhaled steroids by two, and cromoglycate by two. Theophyllines were locally available in all 41 cases, oral salbutamol in 40 , inhaled bronchodilators in 34 , and inhaled steroids (usually beclomethasone $50 \mu \mathrm{g}$ ) in only 15 . Where they were available, the median (range) cost of a beclomethasone $50 \mu \mathrm{g}$ inhaler was $20 \%$ (6.8-100\%) of average local monthly income, salbutamol inhaler $13 \%$ (3.3-250\%), 90 salbutamol $4 \mathrm{mg}$ tablets $3.8 \%(0.8-75 \%)$, and 90 aminophylline $100 \mathrm{mg}$ tablets $4.5 \%$ $(0.5-70 \%)$. If they were available locally at a cheaper price, $34(83 \%)$ respondents would prescribe more inhaled steroids and $37(90 \%)$ would prescribe more inhaled bronchodilators.

Conclusions - Many asthma patients in developing countries are not receiving adequate treatment because the required drugs are not available in their area or are prohibitively expensive.

(Thorax 1997;52:605-607)
\end{abstract}

Department of

Thoracic Medicine,

Killingbeck Hospital,

Leeds LS14 6UQ, UK

J P Watson

Department of

Respiratory Medicine,

Worcester Royal

Infirmary,

Worcester WR1 3AS,

UK

R A Lewis

Correspondence to: Dr J P Watson,

Leeds General Infirmary,

Great George Street,

Leeds LS1 3EX, UK.

Received 18 June 1996

Accepted for publication

28 November 1996
Keywords: asthma, developing countries, anti-asthmatic agents, pharmaceutical economics.

International consensus guidelines on asthma management ${ }^{1}$ recommend regular prophylactic inhaled medication to prevent chronic symptoms, with inhaled bronchodilators as required for symptomatic relief. These guidelines are intended for global application, including developing countries.

Reliable estimates of the prevalence of asthma in developing countries are not available, but the reported rates are generally much lower than for developed countries and are lower in rural than in urban populations. ${ }^{2}$ The increasing urbanisation of many developing countries may be expected to lead to a higher prevalence of asthma in the future.

There is little published information about how asthma patients in developing countries are currently treated. This study aimed to find out what treatment is being prescribed to patients with asthma in developing countries, how it compares with the published guidelines, and what obstacles there may be to implementing those guidelines.

\section{Methods}

A questionnaire was sent to 163 members of the UK Christian Medical Fellowship working in 28 developing countries in Africa and Asia. Most were working in mission or other charitable hospitals and health programmes.

Doctors were asked about the local cost and availability of asthma medicines, the frequency with which they prescribed them, and whether they would prescribe more inhaled drugs if they were available at a cheaper price. They were also asked about local average income, and the income of a local trained nurse. The nurse income was chosen because it was likely to be available to participants, and more reliable than "average income" figures which are difficult to estimate in subsistence farming communities. Details of local facilities and the nearest teaching hospital were requested. There was space for additional comments.

\section{Results}

Forty one replies were received from 24 countries (table 1). Thirty respondents worked in hospitals, 10 in community health projects, and one in a refugee camp. Between them they

Table 1 Countries from which replies were received. Where more than one reply was received, the number is shown in parentheses

\begin{tabular}{ll}
\hline Angola & Mozambique \\
Bangladesh & Nepal (5) \\
Benin & Niger \\
Cameroon & Pakistan (2) \\
Cote d'Ivoire & Sierra Leone \\
Gambia & Sudan \\
Ghana & Swaziland \\
Guinea & Tanzania (4) \\
India & Uganda \\
Indonesia & Zaire (4) \\
Kenya (4) & Zambia \\
Madagascar (2) & Zimbabwe (2) \\
\hline
\end{tabular}


Table 2 No. (\%) of locations where drugs were available and no. of places where drugs were prescribed with different frequencies

\begin{tabular}{|c|c|c|c|c|c|}
\hline \multirow[t]{2}{*}{ Drugs } & \multirow{2}{*}{$\begin{array}{l}\text { Locally } \\
\text { available }\end{array}$} & \multicolumn{4}{|c|}{ Frequency prescribed* } \\
\hline & & $\begin{array}{l}\text { Usually/ } \\
\text { often }\end{array}$ & Rarely & Never & $\begin{array}{l}\text { Not } \\
\text { available }\end{array}$ \\
\hline Oral salbutamol & $40(98)$ & 35 & 4 & 0 & 1 \\
\hline Theophyllines & $41(100)$ & 30 & 8 & 1 & 0 \\
\hline Slow release theophyllines & $11(27)$ & 5 & 2 & 3 & 30 \\
\hline Inhaled $\beta$ agonist & $34(83)$ & 12 & 18 & 4 & 7 \\
\hline Inhaled anticholinergic & $2(5)$ & 1 & 0 & 0 & 39 \\
\hline Inhaled steroid & $15(37)$ & 2 & 8 & 3 & 26 \\
\hline Cromoglycate & $7(17)$ & 2 & 1 & 3 & 34 \\
\hline \multicolumn{6}{|l|}{ Admitted patients: } \\
\hline Nebulised salbutamol & $19(46)$ & 12 & 2 & 5 & 22 \\
\hline Nebulised ipratropium & $1(2)$ & 1 & 0 & 0 & 40 \\
\hline
\end{tabular}

* The numbers do not add up to 41 because some respondents left blanks.

Table 3 Median (range) cost of drugs in UK pounds and median (range) cost as percentage of average local income and income of a trained nurse

\begin{tabular}{llcc}
\hline Drug & Cost $(\text { UK })^{*}$ & \% of local income & \% of nurse income \\
\hline Oral salbutamol & $0.65(0.08-20.00)$ & $3.8(0.8-75)$ & $2.2(0.3-43)$ \\
Aminophylline & $0.80(0.10-13.33)$ & $4.5(0.5-70)$ & $2.1(0.3-28)$ \\
Salbutamol MDI & $2.60(0.36-10.00)$ & $13(3.3-250)$ & $6.7(1.3-100)$ \\
Beclomethasone dipropionate & $3.12(1.41-7.28)$ & $20(6.8-100)$ & $7.5(3.0-50)$ \\
$\quad$ MDI & $4.54(2.00-7.28)$ & $25(15-48)$ & $17(6.0-20)$ \\
\hline
\end{tabular}

* Costs are for 30 days supply of tablets or one metered dose inhaler (MDI). Beclomethasone costs are for $50 \mu \mathrm{g} /$ dose inhaler. was $£ 14.31(£ 2.00-£ 151.52)$. The median nurse income was $£ 25.36$ ( $£ 5.00-£ 360.00)$.

The median cost of drugs in UK pounds is shown in table 3 and, where available, as the proportion of average local monthly income and nurse income. If they were available locally at a cheaper price, $34(83 \%)$ respondents said they would prescribe more inhaled steroids and $37(90 \%)$ that they would prescribe more inhaled bronchodilators.

ADDITIONAL COMMENTS

Several doctors commented that they were aware that the treatment they offered was far from optimal but they were constrained by economic realities. Many complained that intermittent availability of some drugs made regular treatment impossible. Some thought that the costs of drugs were unnecessarily inflated. Patient education was also seen as a problem. There was a reluctance to accept asthma as an incurable illness needing long term medication.

\section{Discussion}

This survey shows that the treatment received by many asthmatic patients in developing countreated approximately 14000 asthma cases annually.

Twenty five (61\%) of the 41 doctors worked in rural locations and $16(39 \%)$ in urban areas. The median distance to the nearest teaching hospital was $180 \mathrm{~km}$ (range $2-1500 \mathrm{~km}$ ), with a median journey time of six hours (range 10 minutes to one week). These figures excluded the two working in teaching hospitals and the doctor who commented "We are all there is, people will come 1000 miles to us".

\section{FACILITIES}

Electricity was available (at least part of the time) in 35 of the 41 centres. Oxygen was available in 23 places, and nebulisers in 19 (15 electric, three foot pump, and one hand operated). Twenty six doctors had peak flow meters, and only three had access to spirometric equipment.

\section{PRESCRIBING}

The number of places where drugs were locally available, and the frequency with which they were prescribed for asthma, are shown in table 2 . In most cases where inhaled steroids were available the only dose was beclomethasone $50 \mu \mathrm{g}$. The two respondents working in teaching hospitals had prescribing patterns similar to those in more remote situations because the cost of inhaled treatments, particularly steroids, was too high for most patients.

Cost

In $18(44 \%)$ centres the patient had to pay the full cost of their drugs. Elsewhere, some subsidy (rarely above 25\%) was provided by government or charity. The median (range) of average monthly local incomes (where given) tries falls far short of international guidelines.

There is a reliance on oral rather than inhaled therapy, and prophylactic medication is rarely prescribed. This is primarily because the required drugs are not available where the patients live, or they are prohibitively expensive for long term use.

There are advantages in a survey of expatriate doctors, although they may not be representative of local medical practice. Most work primarily in voluntary capacities (rather than in private practice treating a wealthy minority). Most were trained in the United Kingdom and have access to some journals including the $B M F$ which published the British Thoracic Society asthma guidelines. ${ }^{3}$ Differences in medical education or ignorance of modern asthma management are unlikely to have influenced the responses. We believe that our results probably represent close to the best care available to the majority of patients with asthma.

The response rate $(25 \%)$ was relatively low. However, in some cases more than one questionnaire was sent to the same institution, some doctors were on home leave at the time of the survey, others may not treat asthma, and some questionnaires may have been lost in the sometimes unreliable postal systems. The replies received represent the care available to approximately 14000 asthmatic patients in 24 countries, which we believe is sufficient to enable valid conclusions to be drawn.

We have no information on treatment in "local" teaching hospitals. However, even if they provide better treatment, this is of little relevance for those living in remote areas. For the patients of most respondents, travel to the nearest teaching hospital would be impractical.

Our results suggest that little has changed in the 20 years since problems of continuity of drug supply, cost, patient education in inhaler use, and the hazards of oral steroids were re- 
ported in Nigeria. ${ }^{4}$ There have been few other studies of asthma treatment in developing countries. In Addis Ababa, Ethiopia, all patients had previously tried traditional remedies (without success) and the most common treatment was oral combination bronchodilators. ${ }^{5}$ A survey of general practitioners in Punjab, India revealed overuse of ephedrine and underuse of inhaled drugs, oxygen, and peak flow meters. ${ }^{6}$ It was suggested that doctors needed better education. In our survey financial constraints were a greater obstacle to effective treatment than the doctors' knowledge.

Inhaled steroids were cost effective in Sri Lanka ${ }^{7}$ in a group of children with moderately severe asthma from predominantly higher social class families who could afford private medical care. This group is unlikely to be representative of most patients in developing countries. The mean monthly cost of $£ 6.16$ for the optimised treatment in that study would be too expensive for most of the patients cared for by the doctors in our survey, being about half the median monthly income. Most of the patients in the Sri Lankan study had been previously treated with long term oral $\beta$ agonists and theophyllines. The suggestion in the accompanying commentary ${ }^{8}$ that this was probably different from the pattern of treatment elsewhere in the developing world is contradicted by our results.

In 1990 the World Conference on Lung Health called on the WHO, governments, nonGovernmental Organisations, and health professionals worldwide "to fight asthma where the disease is now largely untreated through strategies to bring care to people throughout the developing world". ${ }^{9}$ This challenge remains today. The problem, as ever in the developing world, is the lack of resources, as neither governments nor patients can afford to pay for the treatment. The challenge should be addressed to the pharmaceutical industry to make effective inhaled medication, particularly prophylactic drugs, available at prices which are realistically affordable. Until then, the comment one doctor added to his reply will remain true: "The poor die, the rich live, matter of cash, really sad."

We thank Dr David Clegg, Overseas Support Secretary, and the staff of the Christian Medical Fellowship for their help in the distribution of the questionnaire, and all those doctors in developing countries who participated in the survey. The cost of this study was funded by MedicAid Ltd. Dr Watson's post at the time this study commenced was supported by a research grant from Allen and Hanburys Ltd.

1 Global Initiatives for Asthma. Global strategy for asthma man agement and prevention. NHLBI/WHO Workshop report. Bethesda, MD: National Institutes of Health, 1995.

2 Cookson JB. Prevalence rates of asthma in developing countries and their comparison with those in Europe and North America. Chest 1987;91(Suppl):97S-103S.

3 British Thoracic Society. Guidelines for the management of asthma: a summary. BMF 1993;306:776-82

4 Warrell DA, Fawcett IW, Harrison BD, Agamah AJ, Ibu JO, Pope HM, et al. Bronchial asthma in the Nigeria Savann Region. $Q \mathcal{F}$ Med 1975;174:325-47.

5 Teklu B. Bronchial asthma at high altitude: a clinical and laboratory study in Addis Ababa. Thorax 1989;44:586-7.

6 Bedi RS. Asthma management by private general practitioners of Punjab. Indian 7 Chest Dis Allied Sci 1994;36:9-13.

7 Perera BJC. Efficacy and cost effectiveness of inhaled steroids in asthma in a developing country. Arch Dis Child 1995; 72:312-5

8 Costello A, Woodward D. Efficacy and cost effectiveness of inhaled steroids in asthma in a developing country. Commentary. Arch Dis Child 1995;72:315-6.

9 Murray JF, Enarson DA. World Lung Health: a concept that should become a reality. Am Rev Respir Dis 1992;146: $818-22$ 